\title{
Marketing English Language Services to a Mature Audience: A Comparative Study of Japan and South Korea
}

\author{
Jeremy Chambers \\ ADVAN College of Foreign Languages, Japan
}

\begin{abstract}
How to cite this paper: Chambers, J. (2018). Marketing English Language Services to a Mature Audience: A Comparative Study of Japan and South Korea. The Educational Review, USA, 2(11), 514-525. http://dx.doi.org/10.26855/er.2018.11.002
\end{abstract}

Corresponding author: Jeremy Chambers, Ph.D., ADVAN College of Foreign Languages, Japan.

\begin{abstract}
As the population of the world ages there is increasing need for an assessment of the marketing strategies that are used to target the elderly. The literature relating to the marketing of foreign languages to the elderly is sparse. Although academicians are divided on the specific age at which a customer transcends to the mature market many agree that this market can begin with members 50years and over. Neilson and Curry (1997) and Moschis (2003) have written in depth expositions on the strategies that ought to be used in respect to members of the mature audience. Using the Moschis Framework, this research explored the marketing techniques used by private English conversation schools in Japan (called eikaiwas) and South Korea (referred to as hogwans) to attract members of the mature audience. A qualitative approach was used to garner the data needed using in depth interviews and archival research. Twelve participants were interviewed. These participants were School Presidents, Administrators and Marketing Officers from Japan and South Korea. The results showed that Japan and South Korea enacted very different marketing strategies in respect to members of the mature audience. Japanese marketers are more prone to appeal to the younger self referent ages of the elderly through their use of younger looking models, brighter colored pamphlets and creative settings for advertisements. Koreans are more conservative in their approach and are inclined to appeal to the nationalistic tendencies of older Koreans. However, both groups use similar segmentation techniques with age being the dominant variable. It is recommended that further research incorporates other segment of the mature audience like the very old and be expanded to look at the marketing strategies that could be effective in marketing online English courses to Asian customers 50 years and over.
\end{abstract}

Keywords

Andragogy, Gerontography, Marketing, ESL, Japan, South Korea

\section{Introduction}

The Department of Economic and Social Affairs Population Division of The United Nations (2015) in its World Population Ageing Report reports that Japan is now faced with an aging population and is poised to have the most remarkable increase of persons living over the age of 80 years than any other nation on the planet. Japan is one of the 6 countries worldwide which contains half of the world's aged population behind China and the United States. The report projects an increasing trend for the Republic of Korea and other Asian states. 
The implication of an ageing population is far reaching and the education industry is not exempt. Private English education courses are widely accessed all over the island but more so in urban areas with specific focus on the young. Like Japan, South Korea is also facing an aging population and therefore it is critical to investigate how private English Schools deal with this from a Marketing and Promotions perspective. The South Korean comparative angle will seek to identify whether similar approaches are used and whether any differences are attributable to culture or economics.

Neilson and Curry (1997) proffer that the 50+ age group is the single longest life stage. Therefore, there is no mistaking the lifetime value of the mature market. The literature relating to the packaging of educational services to the elderly is visibly sparse with more scholars focusing on health, financial and governmental services.

The Japanese English Industry is divided into two parts. One part deals with English as a school subject and follows strict curriculum rules in order to prepare clients for particular exams such as High School and University Entrance exams and the Eiken tests. The other part deals with English as a communicative tool and targets people that use English as a means of international communication. This part is known as Eikaiwa and forms the foundation of this study.

Pennycook (2004) in describing this industry explains that English continues to be the gatekeeper to amplify socio economic power and status and is sometimes used as a class marker. Hadzantonis (2013) asserts that this has spurred a new drive in all areas of the market to achieve competency in English Language as a national economic developmental strategy.

It has been long thought that older people make poor students of second languages. However seniors have begun to prove all types of stereotypes wrong. Reports have continued to surface especially in some parts of Asia such as China and Japan of an upward trend in language education enrolments by persons 50 years and over (Anderson, 2012). The author explains that there is an increasing trend among American seniors travelling abroad to engage in language immersion classes.

This study aims to critically assess the techniques used by private English schools in Japan and South Korea in targeting and marketing to mature audiences and to make recommendations on how to improve the effectiveness of their tactics.

\subsection{Research Objectives}

1. To critically assess the marketing strategies used by Japanese Private English Schools as well as Korean English schools.

2. To identify any similarities or differences in marketing activities used by both countries and to ascertain what may be the root cause of such differences.

3. To ascertain the proportion of mature students who attend private English schools in relation to the general student body of those schools with the aim of developing a general profile of the student.

4. To ascertain the financial viability and willingness of the investigated schools to serve this segment of the market.

5. To propose ways in which schools may wish to configure their techniques in reaching a more mature audience in response to current trends and based on the information unearthed through this study.

\section{Review of the Literature}

\subsection{Heterogeneity within the Mature Audience}

Several academicians have offered several means of segmenting the mature audience based on demographic, psychographic and gerontographic variables (Moschis, 2003; Michman, Mazze and Greco, 2003; Lazer, 1986; Bone, 1991). A central theme throughout academic publications is that chronological age should not be relied on as a significant segmentation variable. The elderly differ from other consumer groups (Moschis, 2003) and require strategies that appeal to their self referent ages (Mattila, Karjaluoto and Pento, 2003). The elderly prefer products and services that allow them to feel younger and reinforce their continuing independence and connectedness to the society. Carrigan (1998) expounds that this need for social interaction makes 
the mature audience a prime target for relationship marketing techniques. The mature audience is information driven and require clear content rich infomercials (Moschis, 2003). They are not as price sensitive as younger cohorts but discounts on standardized products do appeal to them (Moschis, Curasi and Bellenger, 2003). The mature market is said to be less self absorbed than younger cohorts and thus the concept of lifelong learning appeals directly to them (Michman, Mazze and Greco, 2003). This is reinforced by the Activity Theory of Aging which explicates the need for the continued connection of the elderly to society through their engagement in multiple activities ranging from civic and community ventures to educational and leisure activities.

Neilson and Curry (1997) state that 'mature audiences are the most diverse and idiosyncratic of all other segments and developing marketing techniques to attract them require careful thought' (p. 311). Marketing campaigns that target the elderly should use bright, bold confident imagery of the aged and reflect a 'can do' attitude. But Moschis (2003) cautions against this 'can do' technique which some marketers have taken too far resulting in somewhat of a 'primrose path,' a tactic which some companies use to attract older audiences. This should be avoided at all cost as it is the same as an over promise and will ultimately be viewed negatively by the elderly who have gained years of experience simply because of their ages. Wolfe (1990) concurs and advises that: "The less absolutely a product is defined, the greater the likelihood that consumers will define the products attributes using their processes of imagination...." (p.28). Neilson and Curry (1997) extends this concept of conditionality arguing that it should be at the epicentre of any marketing strategy used to reach members of a mature audience. This conditionality means that older persons will not be lead or seemingly coerced into arriving at the decision that the marketer wishes them to have.

The peculiarity of the Aged distinguishes them from other consumer groups on a number of platforms including information processing ability, consumption, agreeability, and marketing expectations. Their idiosyncrasies directly relate to the marketing techniques that they are most susceptible to and their inherent need for control. Greco (1987) explains that marketing techniques should be kept as simple as possible. This simplicity reinforces the mature audience's competency and ultimately supports the 'can do' attitude that should be reflected in advertisements geared towards them. These assertions seem to come into direct contravention with later research undertaken by Wolfe (1990) who postulates that mature audiences have a highly developed 'whole picture orientation' and thus appreciate content rich marketing techniques. Because of the fullness of their life experiences there is a need for clarity and information centred promotion. So, marketing communication techniques should be complete, straightforward and detailed. This is the opposite approach to marketing to youth audiences which require a splintered, quick hyper-language approach using shorter advertisements over multiple channels (Spero and Stone, 2004).

\subsection{Segmenting the Mature Audience}

Traditionally, segmentation has been primarily based on demographic variables making age a prime variable for segmentation but because of the heterogeneity of the mature audience it is critical that this consumer group be segmented using multiple variables. Michman, Mazze and Greco (2003) proffer that retirement status as well as life stage segmentation and buying behaviours are also other variables that can be used to segment the market for the aged. Perceived age may be relied on as another segmentation criterion. It speaks to the age that older people view themselves as being. This perceived age is usually younger than the chronological age and drives consumption behaviour. Ying and Yao (2010) found that in China the self perceived age of senior citizens is younger than their physiological age. Treguer (2002) explains that persons over 50 years tend to have a self perceived age that is between 10-15 years younger than their life age. These younger ages can be used to reflect the lifestyle that this segment wishes to enjoy and maintain and should enable the development of marketing strategies that target the perceived ages of seniors rather than their chronological ages.

Lazer (1986) highlights: members 55-64years are known as the 'Younger Olders', 65-74years are the 'Middles', 75-84years 
are the 'Seniors' and 85years and over are known as the 'Very Old'. Similarly Gordon, Moser and Warren (2002) developed another classification for the aged. Those between 55-65 years are known as the 'young matures', 65-75 years as the 'middle matures', and those over 75 years the 'older matures'.

Moschis (2003) classification outlines the "Healthy Hermits" who are psychologically withdrawn, the "Ailing Outgoers" who have positive self esteem and self concept and are still interested in getting the most out of life; the "Healthy Indulgers" who differ the least from the younger generation of Baby Boomers and are socially engaged and have strong need for selective information. They are cognitively younger than their counterparts and exude higher self confidence and are less price sensitive; and finally the "Frail Recluses" who have experienced the largest number of life changing events.

\subsection{Marketing to the Mature Segment}

Lazer (1986) advises that marketers should see the mature segment as the 'second youth market'. Marketing strategy should utilize themes that allow the aged to feel, look and act younger and reinforce their enduring connection to society. Benefits and not features should be sold. Moschis (2003) supports this point by arguing that the positioning of the advertised service is dependent on the sub segment that is targeted. Each sub-segment within the mature audience responds differently to marketing stimuli.

Michman, Mazze and Greco (2003) argue that in marketing to the mature segment three variables should be considered. Firstly, the service must perform as expected and be supported with guarantees. Secondly, it is imperative that the service has social reinforcement. Lastly, it should satisfy consequential experience expectations. Anjali (2012) addressed the issue of marketing lifelong education to members of the mature audience. The author propounds that the activity of marketing lifelong education to the elderly requires a multimedia approach which blends traditional forms and rituals of the domestic society within which the elderly live with interpersonal communication channels relevant to their changing needs. Educational services must be marketed as empowerment tools which enable the elderly to remain connected to the changing world around them. Singh (2001) cements this argument by explaining that the communal nature of Asian societies requires that the marketing of educational services to the elderly highlight how the knowledge gained by them can be used to benefit the society.

Older consumers do not relate to older models (Moschis, 2003). The longevity of remaining life for the mature consumer should take pride of place in any organization's marketing tactic which may account for not using older models in advertisements to the elderly. Conversely, Carrigan and Szmigin (1998) argue that older consumers welcome advertisements that feature healthy and vigorous consumers of older ages. Using older models will deter against the disengagement of the elderly from society and positively influence their self esteem. Older consumers are more likely to believe information coming from middle-aged and older models than young models in identical advertisements (Milliman and Erffmeyer, 1990).

Moschis (2003) argues that there are six creative positioning platforms that may be used when marketing to members of the mature audience. These are: convenience, quality, dependability, product development, personalized service and functionality. Like some of the others Leventhal (1997) proposed another set of criteria which should be imbedded in any marketing strategy aimed at reaching the mature segment of the market. These five key concepts are: autonomy, connectedness, altruism, personal growth and revitalization. These theorists agree that 'old' should never be communicated when advertising to the mature segment but themes of socialization, being able to do things with one's peers, and empowerment should be accentuated.

Members of a mature audience have a strong need to have trust in a company and are more responsive to emotional stimuli (Leventhal, 1997). A multigenerational interactive approach is necessary in order to show older consumers that the company is able to add value to the lives of consumers of other segments supporting the 'same person' concept as explicated by (Moschis, 2003). Although the elderly may differ significantly from other market segments and among themselves, Semon (1995) concludes that a central characteristic common to the elderly is brand loyalty. Carrigan (1998) explains that the elderly crave sup- 
port and social interaction. Therefore, relationship marketing should take precedents over a transaction approach when dealing with a mature audience. The Kang and Ridgway conceptual model has also been used to explain the development of relationship marketing strategies to the elderly. The search for social support is cogent in the buying behaviour of older consumers and therefore developing relationship marketing strategies to serve their needs is critical (Carrigan, 1999).

\section{Methodology}

The epistemological approach used was Social Constructionism. Because this research primarily subtends on an assessment and critique of marketing techniques used by Japanese and Korean practioners, both primary and secondary qualitative data were gleaned by means of semi-structured interviews and archival research. Sixteen semi-structured interviews were conducted with participants from Japan and South Korea. The interviews were conducted in two phases commencing with Japan then South Korea. All participants were engaged in some form of marketing activity on behalf of their English School and were able to make strategic decisions on behalf of their company. All interviews were conducted in English. Theoretical concepts relating to Gerontographics, Relationship marketing and Services marketing were used to formulate the interview questions. Respondents were asked to supply answers to approximately 40 questions. The list of questions was divided into three parts: The Mature Customer, Marketing Strategy, Profitability/Effectiveness. Archival research was also conducted on marketing records held by the English schools.

After the data collection and assembly from both countries, data reduction took place. To protect the identity of participants each participant was given an alphanumeric identifying pin.. Data coding was used to break down the information collected into discrete chunks that could then be analyzed. Content analysis technique was used to condense the data collected and structure it according to the existing categories prescribed. The presence of certain concepts within participants' responses were therefore quantified and conclusions drawn.

\section{Findings}

\subsection{Segmentation and Marketing Strategies}

Based on the responses of the Japanese respondents the average age of the senior citizens served is 54 years. The Korean respondents reported that the average age of the mature client at their schools is 56 years. All the respondents confirmed that older clients were the most loyal and had the lowest rate of defection. When asked to categorize the typical customer based on the Moschis' Framework the 12 participants selected Healthy Indulgers. The recurring reasons cited related to mobility, age, lifestyle and sociability. All 12 participants cited lifestyle as one of the reasons for selecting the "Healthy Indulgers" category. Five respondents mentioned sociability.

Of the eight Japanese respondents six agreed that seniors were more likely to sign up in pairs or groups. They explained that this is attributed to the special classes designed for seniors, the group packages that are also offered to them and the fact that some marketers target Japanese companies by offering packages for their senior executives or recently retired staff. However, all four Korean respondents reported that seniors were more likely to sign up individually. Three respondents cited that because no specialist courses are offered to seniors this may account for them not signing up in pairs.

All respondents reported that age is used as the main segmentation variable. Three Korean respondents reported using age as well as location and discretionary income; while six Japanese respondents reported depending on age as well as lifestyle more than any other segmentation bases. For Koreans there is an emphasis on older people with higher discretionary income. This is because it reflects their ability to pay. The Japanese target the healthier more outgoing elderly consumer. They believe that these persons are more suitable for English education because they are more sociable and have a greater level of curiosity 
which will help to sustain their interest in the courses.

All participants reported that they advertise to persons 50 years and over. Both the Japanese and Korean respondents cited the aging population as the main reason. Two Japanese and three Korean respondents also cited increased travel to overseas countries by the elderly as another reason for beginning to market English courses to them. Five Japanese and one Korean participant, whose schools are engaged in the practice of marketing to the elderly for ten years and over, reported significant chan ges in their marketing strategies. The Japanese schools reported that previous techniques were more nationalistic and inward looking and depended on showing English education within the context of contributing to Japanese society and business. But now marketing techniques have begun to focus on the elderly as individuals who wish to extend the enjoyment of their lives and not in terms of their productive capacity to the nation. Because of this the Japanese respondents have begun to use younger looking models and have positioned English education as a pastime to be enjoyed.

Of the four Korean participants three reported that they have not made any significant changes to the techniques used to market to the elderly. They have continued to rely on past approaches which meant positioning English education in the context of the nationalistic pride of the Koreans and the global advancement of Korean businesses and resources.

Seven of the eight interviewed participants in Japan reported relying on print media as the main marketing tool for the elderly. One school relied more heavily on TV. All Korean participants reported using print, specifically pamphlets, as the main marketing channel. No respondent reported using radio as a marketing medium to target the elderly. Japanese and Korean respondents who reported relying more on print advertisement as the main medium to market to the elderly gave the following reasons:

1) It is cheaper and has a wider spread.

2) More information can be placed in print ads than electronic ads such as TV and radio.

3) The elderly like to read so print ads appeal more to them.

4) Print ads in terms of pamphlets and community notice board advertisements can be designed and printed in-house.

5) Because the elderly do not have a large percentage contribution to gross margin a cheaper medium has to be used to target them.

Seven Japanese participants acknowledged that they used younger looking models. Five Japanese schools capitalize on the mobility of their target audience by showing these models talking with foreigners in informal settings such as Izakayas, restaurants or on the Shinkansen or on camping trips and overseas travel with peers. Some of the reasons cited by the Japanese were that younger looking models are more appealing especially if you wish to reinforce a particular lifestyle among the elderly. One participant explained that because higher prices are sometimes charged for specialist courses targeted to the elderly he felt it better to use younger models who are better able to capture and portray the essence of the courses offered.

Korean schools used models closer to the chronological ages of their target audience. Three respondents agreed that elderly consumers may be more willing to listen to advice coming from other elderly consumers than they would from younger consumers given the hierarchical nature of the Korean society and the pre-eminence that chronological age still has in daily life in Korea. Two respondents believed that more respect is to be had from using older models to appeal to older Korean customers. Developing a positioning strategy is necessary given the heterogeneity of the age and the multiplicity of competitors that have now recognized the affluence of this segment. Following the clear distinctions that could be seen between the Koreans and the Japanese in regards to the use of older models in advertisements which target the elderly; there were similarities and differences between the creative themes that were used for these same advertisements. The 8 Japanese respondents alluded to social interaction, youthful excitement and leisure as the three most central creative themes used in designing their marketing campaigns which target the mature audience. These are reinforced with the use of younger looking models, jingles, bright and bold 
imagery as well as creative settings which range from in-class pictures, outdoor activities and overseas travel. The Korean respondents tended to report the use of connectedness to society and national pride to position English education for the elderly. Older looking models that appear active and healthy are used.

Of the twelve participants that were interviewed eight practiced any type of formal relationship marketing initiative specifically for the elderly. Five Japanese and one Korean participant reported that ICT media is used to develop relationships with older attendees at their institutions. Three Japanese respondents use an application called LINE which is popular in Asia and form forums where more mature customers can interact with each other in English. The single Korean participant that reported using ICT media uses an email forum for the elderly but reported that it wasn't as effective as she would hope it to be. Four respondents use newsletters. Two participants had a birthday club for seniors and one had quarterly outings to Japanese onsens. Two Korean schools explained that they use price as a relationship marketing tool to also build customer loyalty among the elderly. Three Japanese participants answered that the customization of courses to match the needs of the elderly was also a relationship marketing strategy that was relied on. One Japanese interviewee explained his use of social bonds whereby tutors for the specialized courses for the elderly were encouraged to form social relationships with seniors outside of normal class hours.

\subsection{Profitability/Effectiveness of Marketing Campaign}

To measure the profitability and/or effectiveness of any given marketing campaign several tactics can be used. An effective measure is by response rate. Korean respondents reported that approximately $10 \%$ of their schools' population is made up of persons 50+ years. The Japanese reported an average figure of $12 \%$. Both countries report a consistent increase in the number of enrolments from mature customers. The average increase from year to year seems to be consistent between both countries. Both countries report an approximate $25 \%$ increase every year for the past three years.

\section{Discussion of the Data}

\subsection{Segmentation and Marketing Strategies}

Both Japanese and Korean schools target mainly the Younger Olders (Lazer's Classification), the Healthy Indulgers (Moschis' Classification) or the New Age Elderly (Mathur's Classification). This profile of the typical mature customer supports the positioning that is used by both the Japanese and South Korean schools. Because this group seeks new experiences and creative personal challenges (Mathur et al., 1998) they may be the most profitable segment for English education in the mature market. They are more loyal and respondents reported that the lower attrition rates among the elderly mirror their higher levels of loyalty. Capitalizing on the loyalty of mature customers is therefore essential to continued profitability. This loyalty should be leveraged to ensure an increase in retention. This can be achieved through referral programs and loyalty schemes. Marketing strategies should therefore appeal to the enduring loyalty of this consumer segment.

Schools in Japan and South Korea target customers on the very edge of the elderly spectrum which leaves a section of the mature audience unaccounted for. Although the majority of respondents stated that a mixture of variables are used in segmenting the market all agree that age is used as the main defining variable. This is used because of its ease and convenience. This practice goes against caution offered by (Greco, 1987; Doka, 1992; Lazer, 1986) who showed that age, whilst useful in segmenting the mature market, can prove to be insufficient because of the heterogeneity that exists within the mature market.

The Japanese's transition from a nationalistic positioning to a more individual positioning, which focuses on the elderly not in terms of his connection to the nation but as his own person, may mirror current trends in the marketing approaches to the elderly where marketing efforts that cause the elderly to 'be' are more well received than other traditional approaches (Gordon, Moser and Warren, 2002). But the enduring nationalistic Korean technique may reflect the undying loyalty that mature cus- 
tomers have to country, products and brands. Lunsford and Burnett (1992) explain that mature customers pride themselves as being more loyal than other age cohorts. Chang (2007) explains the effectiveness of appealing to Korean pride in the positioning of products. This may account for the Korean's continuing positioning success. The impact of Collectivism on marketing cannot be overlooked and must be taken into consideration when analyzing the approach of the Koreans in marketing English education to members of a mature audience. Chang (2007) further explicates the influence of previous governments in South Korea in instilling national pride and how this has served to impact the marketing strategies that have become most successful in that nation.

The marketing channels used by both countries reflect the ongoing marketing culture of both countries. Reliance on print media to reach the elderly has proven to be an effective medium. Picard (2003) explains that the elderly trust written information because of their long marketing experiences with print. The elderly's long exposure with print makes them a prime target for print ads. Using print therefore proves to be an effective way in reaching them. Both Japan and South Korea depend more on print advertisement on reaching the elderly than they do on TV or radio advertisements. This dependence on print agrees with (Moschis, 2003) recommendations for advertising strategy toward the elderly to make use of print. However this non-reliance on TV advertisements deviates from more Western practices which highlights that this segment is the highest among television viewers and thus TV advertisement forms a viable tool to be used when marketing to them. This dependence on print may stem from the Japanese marketing culture which relies heavily on the use of print (Herbig, 1995). It is common practice in the private English school industry in Japan and among the largest private English schools to use pamphlets to advertise their service offerings. Hemsley-Brown and Oplatka (2006) expound on the marketing practices of institutions of higher learning and their inclinations in using print as one of the main media in reaching target groups. One of the foundational rationales rests on the fact that the authors agree that the marketing of education should be seen within the context of service marketing and should be deeply rooted in having high informational content.

Radio is not used as a medium to attract the elderly in South Korea and Japan for English education classes. Heinze (2011) reveals the continued dominance of TV over radio in Asia with less than $40 \%$ of the population in Japan listening to radio at least once a week. Heinze (2011) argues that the Japanese radio generation which is termed 'dankai sedai' is made up of persons born between 1935 and 1954. However, this age cohort also spends more time reading print than they do listening to the radio.

The use of older models is a point of deference between both countries. Japan is more prone to use younger looking models in advertisements to the elderly because of the central creative theme of all their advertisements which accentuates the longevity of life remaining for the elderly and which appeals to their younger self referent ages. This agrees with (Moschis, 2003) assertions that older customers do not relate to older models. The creative positioning of the Japanese advertisements capitalizes on the psychological ages of members of the mature audience and supports the 'can do' attitude. The use of older models by the South Koreans agrees with (Milliman and Erffmeyer, 1990) findings that older customers are more inclined to believe and are better persuaded by older models. But it is arguable that English education is considered an 'age neutral' product and therefore does not require the use of either younger or older looking models. Balaz (1995) argue that the use of models in age neutral services is immaterial in inducing the target audience to purchase. Notwithstanding the type of model used should support the type of positioning that is desired. While the central creative theme for Japanese marketing campaigns rest on showcasing the longevity of life of the elderly and highlighting the social interaction aspects of English education courses that they offer, the main creative theme for South Korean schools subtend on using English as a means of giving back to the community, altruism and selflessness.

Japanese schools are more inclined to use younger models in social settings to advertise to the elderly while Korean schools prefer to use older models. Some Korean schools use an extended family setting while others display single pictures of the el- 
derly. The central theme that is recognizable agrees with (Leventhal, 1997) concept of connectedness. This connectedness is communicated from differing perspectives. Japanese schools continue to stress connectedness in view of social interaction with one's peers. Korean schools position this connectedness in terms of family and community. The Korean type of connectedness seems to rely more heavily on the Asian Confucian belief of aging and wisdom and so positions the elderly model in a role that still makes him central to the continued development of the family and the community. Anjali (2012) supports this by asserting that in marketing education to the elderly it is critical that traditional rituals and culture be retained and blended with more contemporary approaches.

Using Berry (1995) theoretical framework of relationship marketing it is evident that Korean English schools rely more on level one relationship management by way of using pricing incentives through discounts in order to create customer loyalty. Japanese schools rely on levels two and three which are social bonds and structural solutions. Having specialized classes for seniors and other value added benefits such as group trips to English speaking countries create a competitive advantage which these Japanese English schools can leverage. This difference may mirror the underlying differences between marketers of these two countries where Korean marketers see the elderly more as transaction customers and so are more profitable to serve by using pricing as a main tool of inducement to purchase.

\subsection{Profitability/Effectiveness of Marketing Campaign}

Both countries acknowledge that marketing accounts for the majority of the increase in enrolments thus depicting a positive relationship between an increase in senior clientele and the school's marketing efforts. External happenings such as international sporting events also contribute to an increase in enrolments.

\section{Conclusion}

This research assessed how English schools in Japan and South Korea develop and implement marketing strategies in order to reach the elderly and made recommendations on how to improve the effectiveness of the strategies and tactics used. The marketing strategies used by Japanese Private English Schools as well as Korean English schools were critically assessed. Several similarities and differences in marketing activities used by both countries were identified and the root causes of such differences were explored. The proportion of mature students who attend private English schools in relation to the general student body was ascertained which enabled the development of a general profile of the elderly customer targeted which agreed with Moschis (2003) Healthy Indulgers category. The financial viability and willingness of the investigated schools to serve the elderly was also investigated and it was revealed that the elderly segment remains lucrative through their higher levels of loyalty and their proclivity to pay on time.

There are similarities and differences in how seniors are targeted and marketed to in both countries. Some practices follow text book rules while other practices have not progressed in tandem with the West. Some techniques remain culturally embedded while others are more contemporary. Although academicians have long outlined the heterogeneity that exists within the mature segment of the consumer market, Asian practioners continue to use age as the main basis of segmenting the mature market. Current marketing trends and expositions on segmentation have cautioned practioners against the use of age (Greco, 1987; Doka, 1992; Lazer, 1986 and Moschis, 2003). Notwithstanding, marketers from both countries use other variables in tandem with Age. Japanese marketers depend more on lifestyle as a means of determining their prime target within the mature market while Koreans depend on income and location. Marketers in Japan and South Korea target the Young matures sub-segment of the mature market because they differ the least from Baby Boomers and are more susceptible to English Language promotional activities. The younger self referent ages of Young Matures make them prime candidates for educational, entertainment, leisure and sporting services. They are also high consumers of print media which ties in with the fact that both countries rely more 
heavily on the use of print than any other advertising channel. This corresponds with the academic literature on marketing to the elderly which encourages the use of print.

However both countries diverge in respect to the creative positioning used in advertisements designed to reach the elderly. The Koreans are more nationalistic in their marketing programmes whilst the Japanese tend to appeal more to the younger self referent ages of the elderly through their lifestyle with advertisements that create mature excitement and reinforce the longevity of life that remains. This compliments the use of younger looking models by the Japanese whilst the Koreans believe that older looking models are more persuasive in inducing seniors to purchase. This divergence is also evident in the literature with Moschis (2003) proffering that older models do not appeal to a mature audience but Carrigan and Szmigin (1998) objecting by explaining that there is greater believability to be had from the use of older models in promotional activities which target members of the mature audience.

Japan and South Korea rely heavily on the use of pamphlets as an advertising tool to the elderly. However while there are many similarities in the placements of these pamphlets there is great disparity in their design and content. In keeping with the more conservative approach of the Koreans darker colors and older models are used. The mature excitement and lifestyle approach of the Japanese is reflected in their use of brighter colors and younger models. They also satisfy the information need of the elderly by including more information in the pamphlets they receive. This corroborates Moschis (2003) assertions that the elderly tend to be more information driven than younger cohorts and prefer information-centric promotional efforts. Japan and South Korea differ on their use of pricing as a marketing and relationship building tool. Koreans are more prone to offering lower prices to seniors which also corroborates with the use of income as one of their main variables of segmentation. However the Japanese's persuasion is that premium pricing is the preferred approach in respect to members of the mature audience who are less price sensitive. The Japanese design special classes for the elderly while the Koreans do not. However in defence of the Korean's tactic it is arguable that English education is an age neutral service and by not offering special classes for the seniors it reinforces the 'same person' concept that can serve to empower the elderly and cause them to be more satisfied with the service offering.

Both sets of marketers have failed to see the importance of referral programmes as a means of managing relationships and maintaining loyalty among the elderly. However in tandem with price, they have employed different tactics in building relationship with more mature clients. The Japanese have proven more astute in how they have harnessed social media and technology to sustain relationships. They also rely to a lesser extent on the use of price as a relationship building tool but instead use social bonds and value added benefits such as overseas travel and specialized classes. The Koreans rely more heavily on price as both a relationship and a competitive tool and are thus less insulated from competition..

In relation to the objectives of this research similarities and differences in marketing strategies between the Japanese and Koreans were recorded. However the effectiveness of these divergent techniques remains embedded in the prevailing marketing culture of each country and is also impacted by economics.

\section{References}

Anderson, J. (2012). Expanding Horizons: New Languages for the Elderly.

Anjali, P. (2012). Role of Universities in Lifelong Learning for Elderly People. Asian Journal of Home Science, 7(2), 600-660. Balaz, A. (1995). The Use and Image of Mature Adults in Health Care Advertising. Health Marketing Quarterly, 12(3), 13-26. Berry, L. (1995). Relationship Marketing of Services: Growing Interest, Emerging Perspectives. Journal of the Academy of Marketing Sciences, 23(4), 236-245.

Bone, P. (1991). Identifying Mature Segments. Journal of Consumer Marketing, 8(4), 19-32.

Carrigan, M. (1998). Segmenting the Grey Market: The Case for Fifty-Plus Lifegroups. Journal of Marketing Practice: Applied Marketing Science, 4(2), 43-56. 
Carrigan, M. (1999). Old Spice-Developing Successful Relationships with the Grey Market. Long Range Planning, 32(2), 253-262.

Carrigan, M., \& Szmigin, I. (1998). The Usage and Portrayal of Older Models in Contemporary Consumer Advertising. Journal of Marketing Practice: Applied Marketing Science, 4(8), 231-248.

Chang, D. (2007). The We-Me Culture. Marketing to Korean Consumers, 18, 141-157.

Desler, G. (2003). Human Resource Management. NJ: Prentice Hall.

Doka, K. (1992). When Gray Is Golden: Business in an Aging America. The Futurist, 26(4), 16-20.

Gordon, T., Moser, H., \& Warren, W. (2002). Serving the Needs of Mature Citizens: Strategies and Techniques for Targeting the 50+ Population. Services Marketing Quarterly, 24(1), 1-17.

Greco, A. (1987). Linking Dimensions of the Elderly Market to Market Planning. Journal of Consumer Marketing, 4(2), 47-55.

Hadzantonis, M. (2013). English Language Pedagogies for a Northeast Asian Context. NY: Routledge Publishers.

Heinze, U. (2011). Radio and Television Consumption in Japan: A Trilateral Intercultural Comparison with the UK and Germany. Electronic Journal of Contemporary Japanese Studies, 3(5), 14-25

Hemsley-Brown, J., \& Oplatka, I. (2006). Universities in a Competitive Global Marketplace: A Systematic Review of the Literature on Higher Education Marketing. International Journal of Public Sector Management, 19(4), 316-338.

Herbig, P. (1995). Marketing Japanese style. CT: Quorum Books.

Lazer, W. (1986). Dimensions of the Mature Market. Journal of Consumer Marketing, 3(3), 23-34.

Lazer, W., Mura, S., \& Kosaka, H. (1995). Japanese Marketing: Towards a Better Understanding. Journal of Marketing, 49(2), 69-81.

Leventhal, R. (1997). Aging Consumers and Their Effects on the Marketplace. Journal of Consumer Marketing, 14(4), 276-281.

Lunsford, D., \& Burnett, M. (1992). Marketing Product Innovations to the Elderly: Understanding the Barriers to Adoption. Journal of Consumer Marketing, 9(4), 53-62.

Manheimer, R. (2005). The Older Learner's Journey to an Ageless Society: Lifelong Learning on the Brink of Crisis. Journal of Transformative Education, 3(198), 198-220.

Mathur, A., Sherman, E., \& Schiffman, L. (1998). Opportunities for Marketing Travel Services to New-Age Elderly. Journal of Services Marketing, 12(4), 265-277.

Mattila, M., Karjaluoto, H., \& Pento, T. (2003). Internet Banking Adoption among Mature Customers: Early Majority or Laggard? Journal of Services Marketing, 17(5), 514-528.

Michman, R., Mazze, E., \& Greco, A. (2003). Lifestyle Marketing: Reaching the New American Consumer. Westport, CT: Praeger Publishers.

Milliman, R., \& Erffmeyer, R. (1990). Improving Advertising Aimed at Seniors. Journal of Advertising Research, 29(6), 31-36.

Moschis, G. (2003). Marketing to Older Adults: An Updated Overview of Present Knowledge and Practice. Journal of Consumer Marketing, 20 (6), 516-525.

Moschis, G., Curasi, C., \& Bellenger, D. (2003). Restaurant Selection Preferences of Mature Consumers. Cornell Hotel and Restaurant Administration Quarterly, 44(4), 51-60.

Neilson, J., \& Curry, K. (1997). Creative Strategies for Connecting with Mature Individuals. Journal of Consumer Marketing, 14(4), 310-322.

Rhee, Y. (2002). Global Public Relations: A Cross-Cultural Study of the Excellence Theory in South Korea. Journal of Public Relations Research, 14(3), 159-184.

Semon, T. (1995). Gerontophobia in Marketing Research. Marketing News, 29(1), $23-24$.

Sidbury, L., \& Simcock, P. (2009). A Multivariate Segmentation Model of Senior Consumers. Journal of Consumer Marketing, 26(4), 251-262.

Singh, A. (2001). Lifelong Education, Present Status and Future Strategy. Indian Journal of Adult Education, 12(2), 25-37. 
Spero, I., \& Stone, M. (2004). Agents of Change: How Young Consumers Are Changing the World of Marketing. Qualitative Market Research: An International Journal, 7(2), 153-159.

Tre'guer, J. (2002). 50+ Marketing: Marketing Communicating and Selling to the Over 50s Generations. Paris: Palgrave Macmillan.

United Nations. (2015). World Population Ageing Report 1950-2050.

Ying, B., \& Yao, R. (2010). Self Perceived Age and Attitudes towards Marketing of Older Consumers in China. Journal of Family and Economic Issues, 31(3), 318-327. 